\title{
Beta-actin in human colon adenocarcinoma cell lines with different metastatic potential ${ }^{\star s}$
}

\author{
Dorota Nowak, Aneta Skwarek-Maruszewska, Magdalena Zemanek-Zboch \\ and Maria Malicka-Błaszkiewicz ${ }^{\bowtie}$ \\ Department of Cell Pathology, Institute of Biochemistry and Molecular Biology, University of Wroctaw,

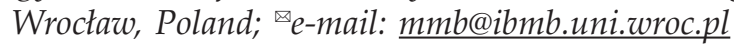

Received: 13 April, 2005; revised: 12 May, 2005; accepted: 13 May, 2005

available on-line: 06 June, 2005

\begin{abstract}
Human colon adenocarcinoma LS180 parental cell line and selected variants, characterized by different metastatic capacity were used to examine, whether a correlation exists between $\beta$-actin expression, its subcellular distribution and metastatic potential of these cells. Cytosolic fraction (supernatant $105000 \times g$ ), isolated from the tumor cells was used as a source for actin quantification. The higher level of $\beta$-actin was observed in the cytosol of three selected sublines to compare with LS180 parental line. Statistically significant increase of $\beta$-actin level in highly motile EB3 cells variant should be underlined to compare with the other sublines. Distinct differences in the phenotype of adenocarcinoma cell variants were found, such as the changes in cells shape, cells spreading and ability to attach to the surface of culture dish. Actin cytoskeleton was visualized with fluorescence microscopy application and microfilaments rhodamine-conjugated phalloidin staining. $\beta$-actin subcellular localization was done by immunofluorescence staining with monoclonal anti- $\beta$ actin antibodies. In the elongated cells (LS180, 3LNLN), this isoactin is dispersed in the whole cell body and concentrates in pseudopods and at the leading edges, when in the rounded variant (EB3) $\beta$-actin dominates mainly in cortical ring under cellular membrane and it is also seen in the subtle protrusions. Summary of our former (Nowak et al., 2002, Acta Biochim. Polon., 49: 823) and current data lead to the conclusion that there is a distinct correlation between metastatic capacity of examined human colon adenocarcinoma cells, the state of actin polymerization, actin cytoskeleton organization and $\beta$-actin expression.
\end{abstract}

Keywords: actin cytoskeleton, $\beta$-actin, colon adenocarcinoma, invasiveness

In vertebrates at least six actin isoforms are expressed in temporally and spatialy regulated patterns. These highly conserved proteins have been classified by both their isoelectric point and primary tissue or cellular localization and comprise $\beta$ and $\gamma$ cytoplasmic, $\alpha$ skeletal and $\alpha$ cardiac and $\alpha$ and $\gamma$ smooth muscle isoactins (Vandekerckhove \& Weber, 1978). Two cytoplasmic isoactins $\beta$ and $\gamma$ are present in non-muscle cells. In these cells actin exists in a dynamic state and can form transitory localized filaments, as it happens in advancing pseudopods of moving cells, in the contractile ring of dividing cells and in regions of active phagocytosis, and also in more permanent microfilaments in specialized regions such as intestinal microvilli. Despite many studies on actin behavior in vitro, the complex dynamics of the actin cytoskeleton required for maintaining the cell shape and cellular locomotion is not well understood (Herman, 1993; Button et al., 1995; Sheterline et al., 1998; Khatilina, 2001).

The existence of multiple actin isoforms within tissues and even within a single cell suggests functional differences among them. Submembrane localization of $\beta$-actin and its participation in active cell movement and wound healing has been shown, while $\gamma$-actin seems to be responsible for maintaining the cell shape and for the differentiation process (see reviews by Nowak \& Malicka-Błaszkiewicz, 1999; Khatilina, 2001).

There are also many questions regarding the correlation between particular actin isoform expression and some cellular pathologies (Chaponnier \& Gabbiani, 2004). Interesting data have been accumulated on the relation between actin organization, the changes in actin isoforms' expression and the ability of cancer cells to form metastases (Verschueren

- Paper dedicated to the memory of Professor Witold Drabikowski and Professor Gabriela Sarzała-Drabikowska. Abbreviations: ABP, actin-binding protein; BSA, bovine serum albumin; DTT, dithiothreitol; FITC, fluorescein isothiocyanate; PBS, phosphate-buffered saline. 
et al., 1994; Pokorna et al., 1994; Janmey \& Chaponnier, 1995; Stournaras et al., 1996; Suzuki et al., 1998; Le et al., 1998; Peckham et al., 2001). The observed reorganization of actin microfilaments in tumor cells may result also from changes in isoactin expression (Le et al., 1998; Shestakova et al, 1999; Peckham et al., 2001). Cytoplasmic $\beta$-actin seems to play an essential role in the "ameboidal" type of movement, characteristic for intravassation of cancer cells through the vessel wall (Khatilina, 2001; Peckham et al., 2001). Increased expression of cytoplasmic $\beta$-actin was found in some tumor cells (Le et al., 1998; Nowak et al., 1999; Nguyen et al., 2000). There is growing interest on the relation between these changes and the invasiveness of cancer cells. However, the published data are often controversial. For example, lymphocytes synthesize $\beta$-actin in remarkable excess relative to $\gamma$-actin, while their leukemia counterparts contain both isoforms in equal proportions. In contrast, M1 myeloblastic leukemia cells contain mainly $\beta$-actin and only after the induction of differentiation, higher expression of $\gamma$-actin is observed in these cells (Nagata \& Ichikawa, 1984).

Special attention should be paid to the results of studies on actin expression in invasive and noninvasive cancer cells (Le et al., 1998; Suzuki et al., 1998; Nowak et al., 2002; Sahai \& Marshall, 2003). The level of $\beta$-actin was found to be much higher in invasive cell lines of sarcoma compared with noninvasive ones. In addition, it was accompanied by changes in $\beta$-actin subcellular distribution and concentration in apical parts of the forming pseudopods, i.e. areas of high dynamics of actin polymerization (Le et al., 1998). However, human salivary gland adenocarcinoma cells are characterized by a decreased level of $\gamma$-actin, accompanied by actin microfilament desintegeration and an increase of the ability of these cells to form metastases compared with noninvasive cells (Suzuki et al., 1998).

In our previous study (Nowak et al., 2002) human colon adenocarcinoma LS180 cell line variants characterized by different metastatic potentials (Opolski et al., 1998; Kieda et al., 2002) were used to examine whether a correlation exists between total actin level, state of actin polymerization and invasiveness of tumor cells. Monomeric $(G)$, total $(T)$ and filamentous (F) actin were determined in the cytosolic fraction of these cells. A statistically significant decrease in $\mathrm{G}$ actin level and an increase in the state of actin polymerization (measured by the $F: G$ actin ratio) were found in the cytosol of three cell variants with a higher metastatic potential and invasiveness (EB3, 3LNLN, 5W) compared with the parental cell line (LS180).

In this paper the same cellular model was used to investigate whether a correlation exists between $\beta$-actin expression, its subcellular distribution and the metastatic potential of human adenocarcinoma sublines.

\section{MATERIALS AND METHODS}

Cells. Human colon adenocarcinoma cell line LS180 and its variants EB3, 3LNLN and 5W were kindly supplied by Professor Danuta Duś from the Institute of Immunology and Experimental Therapy, Polish Academy of Sciences in Wrocław. The cells were propagated in OptiMEM medium supplemented with 3\% fetal bovine serum (Gibco, Grand Island, NY, USA). Cells were cultured in $25 \mathrm{~cm}^{2}$ TC flasks (Falcon or Costar) at $37^{\circ} \mathrm{C}$ in $5 \% \mathrm{CO}_{2}, 95 \%$ humidified air and passaged weekly, using $0.25 \%$ trypsin/ 0.05\% EDTA solution (Gibco, Grand Island, NY, USA) for cell dissociation.

Originally the cell line LS180 was obtained from the Deutsches Krebsforschungszentrum (Heidelberg, Germany). The parental cells (LS180) were later selected and characterized by Opolski et al. (1998) and Kieda et al. (2002). More details on the procedure of cell selection are given in our previous paper (Nowak et al., 2002).

Isolation of cytosolic fraction. Cells were homogenized and the cytosol fraction was prepared as described earlier by Malicka-Błaszkiewicz and Roth (1981). The cells growing on tissue culture dishes were gently washed with PBS, scraped with a rubber policeman and suspended in $\mathrm{G}$ actin stabilizing buffer (freshly made), containing $10 \mathrm{mM}$ Tris/ $\mathrm{HCl}$, pH 7.4, $0.25 \mathrm{M}$ sucrose, $1 \mathrm{mM}$ DTT, $0.1 \mathrm{mM}$ ATP, $0.1 \mathrm{mM} \mathrm{CaCl}$ (buffer A). Cells were centrifuged $\left(100 \times g, 3\right.$ min., $\left.4^{\circ} \mathrm{C}\right)$ and homogenized with 3 volumes of freshly made buffer A in a Dounce homogenizer. The homogenates were centrifuged at 105000 $\times g$ for $1 \mathrm{~h}$, at $4^{\circ} \mathrm{C}$. The high speed supernatant was used as the cytosolic fraction and kept frozen ($70^{\circ} \mathrm{C}$ ) before $\beta$-actin identification and concentration determination.

\section{Microscopic analysis}

Light microscopy. Phase-contrast and differential interference contrast (DIC) microscopy were used to observe the behavior of cells and their morphology under culture conditions.

Fluorescence microscopy. Fluorescence analysis was applied for actin visualization and to study organization of microfilaments. Cells growing on coverslips were fixed with $4 \%$ formaldehyde in 20 $\mathrm{mM}$ Pipes buffer containing $80 \mathrm{mM} \mathrm{KCl}, 1.5 \mathrm{mM}$ $\mathrm{MgCl}_{2}, 1.5 \mathrm{mM} \mathrm{CaCl}_{2}, 10 \mathrm{mM}$ EGTA, $5.6 \mathrm{mM}$ glucose, $\mathrm{pH}=7.2$ (Bond \& Somlyo, 1982) for $10 \mathrm{~min}$ at room temperature and then permeabilized with $0.2 \%$ Triton X-100 in PBS for 10 min. Actin microfila- 
ments were visualized with rhodamine-conjugated phalloidin staining (Molecular Probes Inc., Eugene, USA) for $20 \mathrm{~min}$. After washing with PBS the cells were mounted in fluorescent mounting buffer and microfilaments were observed under a fluorescence microscope Olympus IX70 or a confocal laser scanning microscope Olympus FV500.

$\beta$-actin immunofluorescence. Cells were grown on glass coverslips $(24 \mathrm{~h})$ and then fixed with absolute methanol $\left(10 \mathrm{~min}\right.$, at $\left.-20^{\circ} \mathrm{C}\right)$. The covering solution was aspirated and the cell layer was covered with cold acetone/methanol $(1: 1 \mathrm{v} / \mathrm{v}, 1 \mathrm{~min})$ and washed 2 times with PBS. $\beta$-Actin was visualized by a monoclonal anti- $\beta$ actin antibody conjugated with FITC (clone AC-15; Molecular Probes Inc., Eugene OR, USA), diluted 1:300 in PBS containing 1\% $\mathrm{BSA}$, at room temperature for $60 \mathrm{~min}$. After repeated washing with PBS, the cells were observed under a fluorescence microscope.

Immunoblotting. Cytosolic fraction was used as a source of actin in Western blotting experiments. It was isolated in identical conditions from the parental cell line and from the selected variants. The same amount of cytoplasmic fraction proteins (25 $\mu \mathrm{g})$ was subjected to analysis. Proteins were separated by SDS/PAGE according to Laemmli (1970) and transferred to nitrocellulose sheets by the procedure of Towbin et al. (1979). Monoclonal antibodies directed against $\beta$ cytoplasmic actin (clone AC-15, Sigma) were used for actin identification. Immunoreactivity was shown by the extravidin-biotin peroxidase (Sigma) technique, using 3-amino-9-ethylcarbazole (AEC) (Sigma) as the substrate for peroxidase. The intensity of bands interacting with anti- $\beta$ actin antibodies, was quantified by densitometry, using software Quantity One (Gel Doc 1000/2000, BioRad). The value of $\beta$-actin presented on Fig. 1 for cell variants results from the comparison with the staining intensity measured for parental cell line.

Protein. Protein was determined by the standard Bradford (1976) procedure.

\section{RESULTS AND DISCUSSION}

Human colon adenocarcinoma cell variants of different metastatic potentials were used to continue our studies on the qualitative and quantitative changes of actin in cancer cells (Malicka-Błaszkiewicz et al., 1995; Nowak et al., 1995; 1999; 2002; Otrocka et al., 2001). The present panel of human LS180 colon adenocarcinoma cell was first selected in vitro by triple migration through a Matrigel-coated nucleopore Transwell filter. The first selection resulted in a variant with an increased affinity towards human endothelial cells of secondary lymphatic organ origin (EB3). The in vitro selected EB3 cells were later passaged in vivo in immunodeficient nu/nu mice by various routes of inoculation to select metastatic variants (Opolski et al., 1998). The in vivo selections, performed by serial implantation of selected cell sublines by the different routes (intrasplenic, i.s.; intravenous, i.v.; or intrailleal, i.i.) resulted in cell variants with a higher metastatic activity (3LNLN and $5 \mathrm{~W})$. They grew preferentially as differently localized metastases after implantation via a given route, as compared with the parental cell line LS180.

We recognized earlier these cells (Nowak et al., 2002) as different in respect to the state of actin polymerization. In the light of the interesting data of Le et al. (1998) on a possible major role of $\beta$-actin in cell motility, it was important to compare the level and subcellular distribution of this isoactin in the tumor cells with different metastatic potentials.

Cytosolic fraction, isolated from the parental human colon adenocarcinoma cell line LS180 and the variants of different metastatic potential (EB3, $3 \mathrm{LNLN}, 5 \mathrm{~W}$ ) was used as the source of actin. Proteins were separated by SDS/PAGE and $\beta$-actin was identified by Western blotting with monoclonal antibodies recognizing this isoactin. Quantitative blot analysis was done by densitometry in several experimental cycles. The data obtained for the adenocarcinoma selectants (EB3, 3LNLN and 5W) were compared with those for the parental line LS180 (Fig. 1).

A higher level of $\beta$-actin was observed in the cytosol of the three selected sublines compared with the parental line LS180. Especially the higher level of $\beta$-actin in EB3 cells should be underlined compared with the other sublines (Fig. 1). These cells are more motile than the parental cells, as they were the

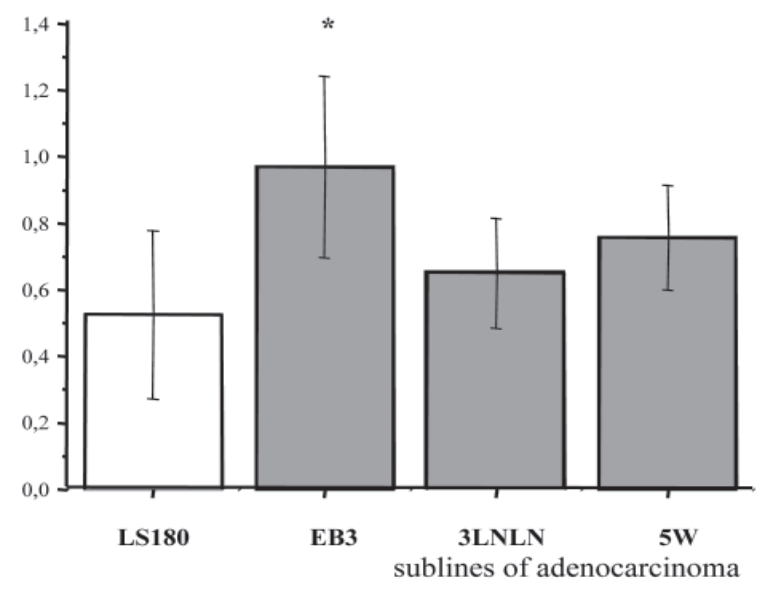

Figure 1. $\beta$-actin expression in human colon adenocarcinoma cells with different metastatic potential.

SDS/PAGE and Western blotting with monoclonal anti- $\beta$ actin antibodies for actin identification and densitometry were applied; $25 \mu \mathrm{g}$ of sample protein was applied in every case. Bars represent the mean from three independent experiments $( \pm$ S.D. $){ }^{*}$ Indicates values significantly different from those for parental line (LS180) as calculated by Student's $t$-test, $P<0.05$. 
first to migrate to the lower surface of the Transwell filter during the selection procedure (Opolski et al., 1998; Kieda et al., 2002).

We looked for a correlation between $\beta$-actin distribution, actin microfilament organization and cell morphology and behavior in culture. Differential interference contrast (DIC), phase contrast and fluorescence microscopy were applied (Figs. 2, 3). The same number of cells from each line was used in comparative experiments. Distinct differences in the phenotype of the adenocarcinoma cell variants were found, such as differences in the cells shape, spreading and ability to attach to the surface of the culture dish (Fig. 2A, B). Thus, parental LS180 cells were of a polygonal, longitudinal shape and formed distinct protrusions (see Fig. 2Aa and $\mathrm{Ba}$ ). In contrast the EB3 cells were rounded and grew in characteristic clusters (Fig. 2Ab and Bb). The EB3 derived 3LNLN cells, selected in vivo from lymph node metastases, resembled in their shape the original LS180 line

A
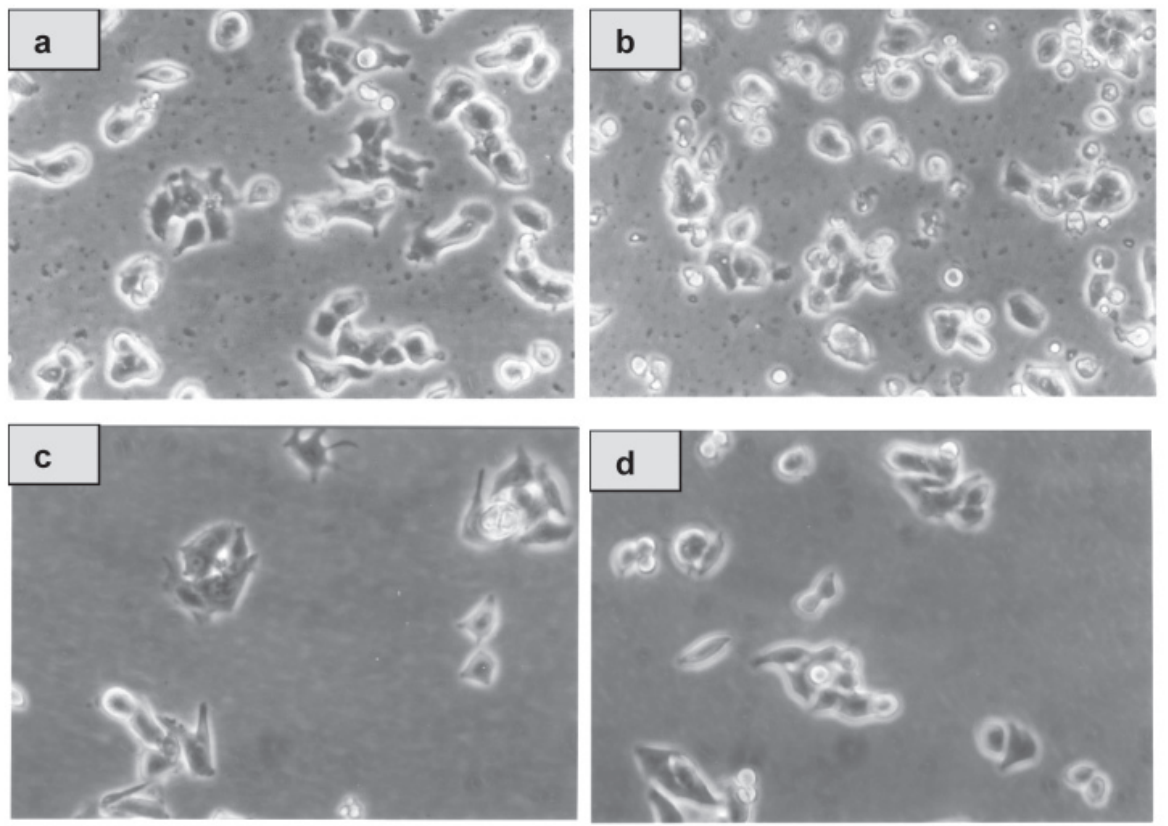

B
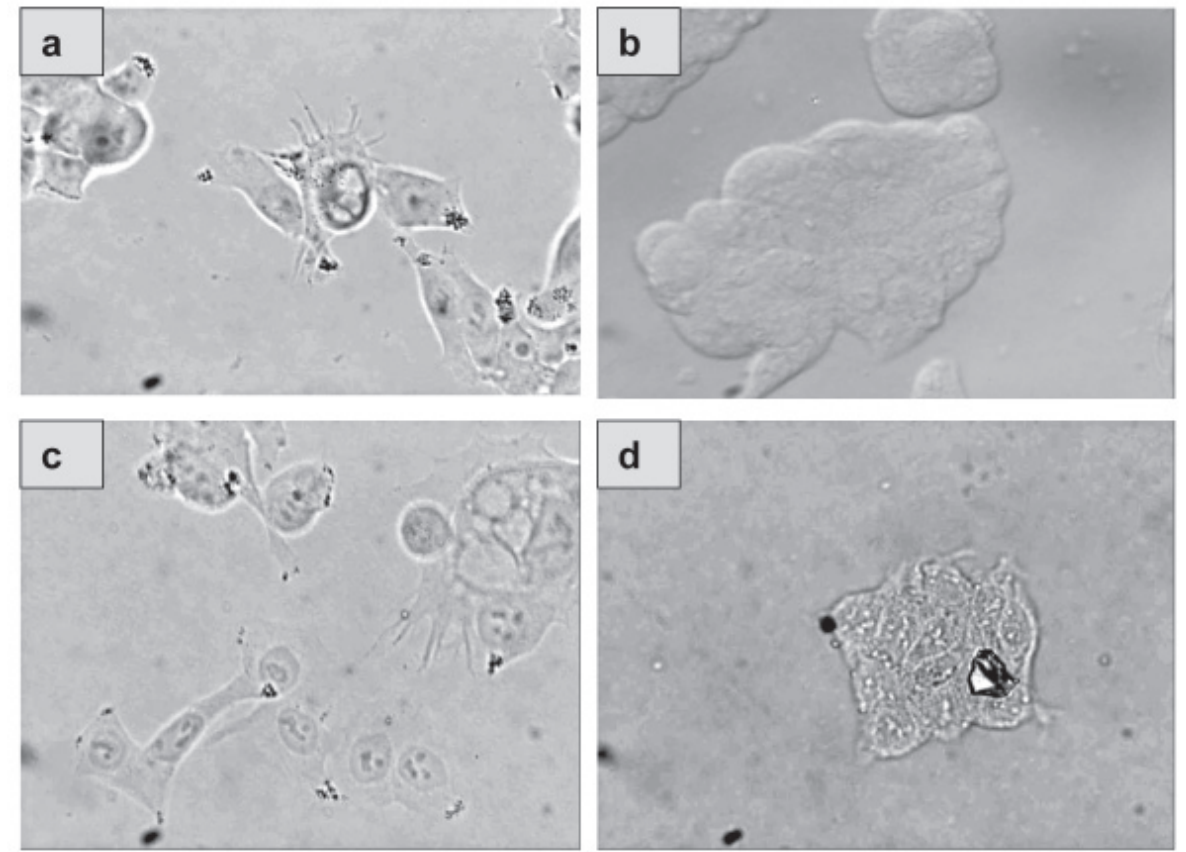

Figure 2. Morphology of human colon adenocarcinoma cell variants.

A. Phase contrast images of cells growing on culture dish (12 h after sieving) magnification 200×; B. Cells observed under differential interference contrast (DIC) microscopy (24 h after sieving) magnification 400×; a, LS180 parental line and variant: b, EB3; c, 3LNLN; d, 5W. 
panel I
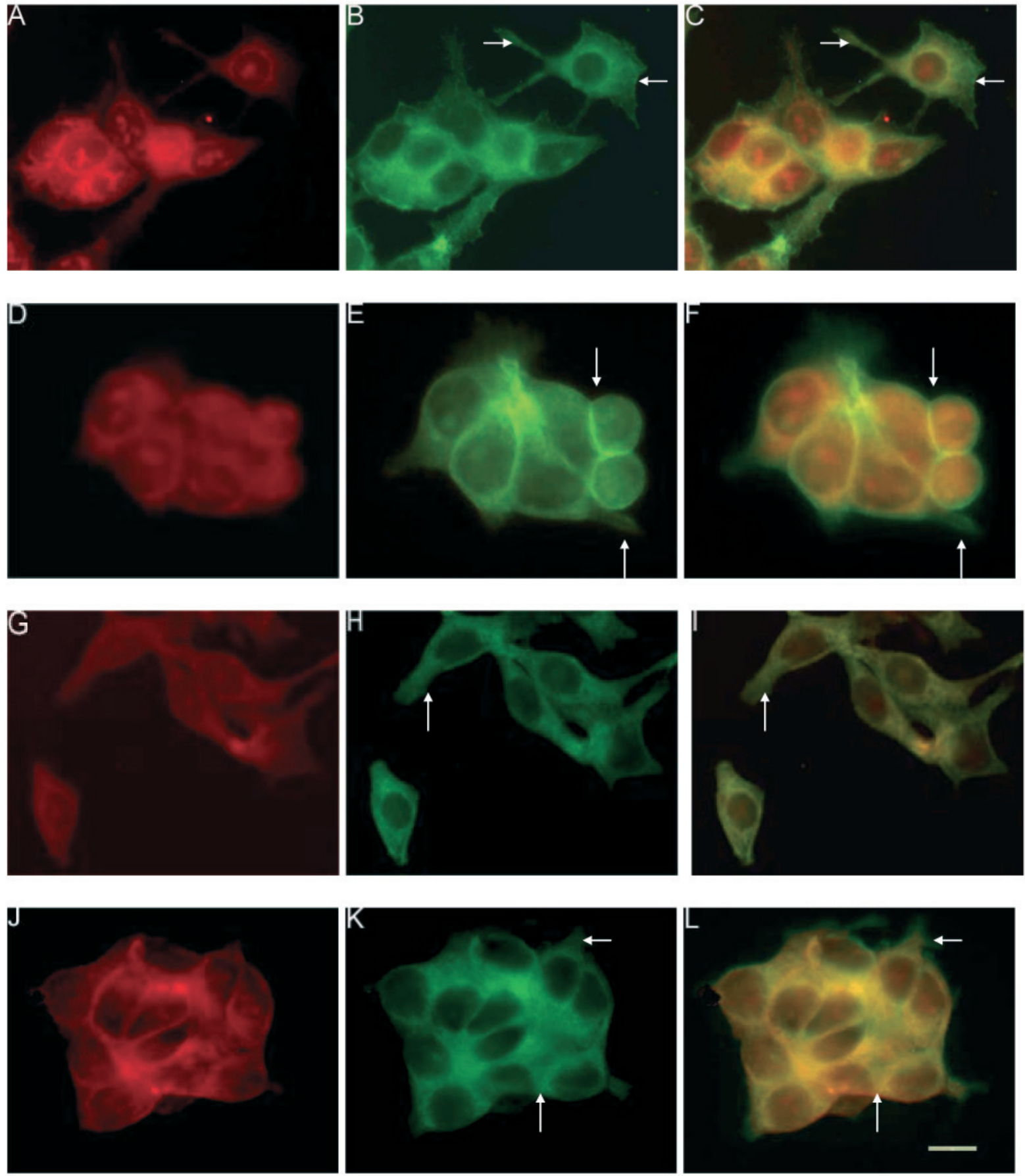

Figure 3. Actin cytoskeleton organization and $\beta$-actin distribution in human colon adenocarcinoma cells with different metastatic potential.

A, B, C - parental LS180 line and variants: D, E, F - EB3; G, H, I - 3LNLN and J, K, L - 5W; scale bar, $10 \mu \mathrm{m}$; obj. $40 \times$ arrows show $\beta$ actin localization in pseudopods, the leading edge of the cells and as a cortical ring under the cell membrane. Panel I: actin microfilaments visualized by rhodamine-phalloidin fluorescence staining. Panel II: $\beta$ actin localization followed by monoclonal anti- $\beta$ actin antibodies conjugated with fluorescein. Panel III: superposition of panels I and II. 
(compare Fig. 2Ac and $\mathrm{Aa}$; $\mathrm{Bc}$ and $\mathrm{Ba}$ ).The highly metastatic $5 \mathrm{~W}$ cells, selected in vivo from liver metastases, looked similar to EB3 cells and also grew in characteristic clusters (Fig. 2Ad and Bd).

Actin cytoskeleton was visualized in the four cell variants by staining microfilaments with rhodamine-conjugated phalloidin and fluorescence microscopy. Similarly to our former hepatoma Morris 5123 experimental rat cancer cell model (Otrocka et al., 2001) and to the observations by others (Le et al., 1998; Suzuki et al., 1998; Nguyen et al., 2000), actin did not form regular microfilaments (stress fibres) in the parental cell line LS180 and in the selected variants. In all the variants actin was dispersed within the whole cell body and created a meshwork (Fig. 3A, D, G, J). In addition, in the rounded cell variants (EB3 and 5W), filamentous actin was rather concentrated under the membrane as a "cortical ring" (Fig. $3 \mathrm{D}, \mathrm{J})$, while in the elongated ones, especially in the parental LS180 cells, actin microfilaments concentrated mainly around the nucleus and were more diffused to the peripheral area of the cells, showing some protrusions rich in filamentous actin (Fig. 3A, $\mathrm{G).}$

A better visualization of the differences in the organization of actin filaments - between the parental LS180 human adenocarcinoma cell line and the first selected, highly motile, metastatic variant EB3 cells is presented in Fig. 4. It also shows the involvement of the actin cytoskeleton in the changes of cell morphology.

The most interesting seems to be our observation on $\beta$-actin identification by its immunofluorescent staining in human adenocarcinoma cell variants, characterized by the different metastatic potential. Monoclonal antibodies to $\beta$-actin conjugated with fluorescein were applied to visualize this isoform within the cell. It allowed us also to observe the subcellular distribution of this isoform. The results of total filamentous actin staining with rhodamine-

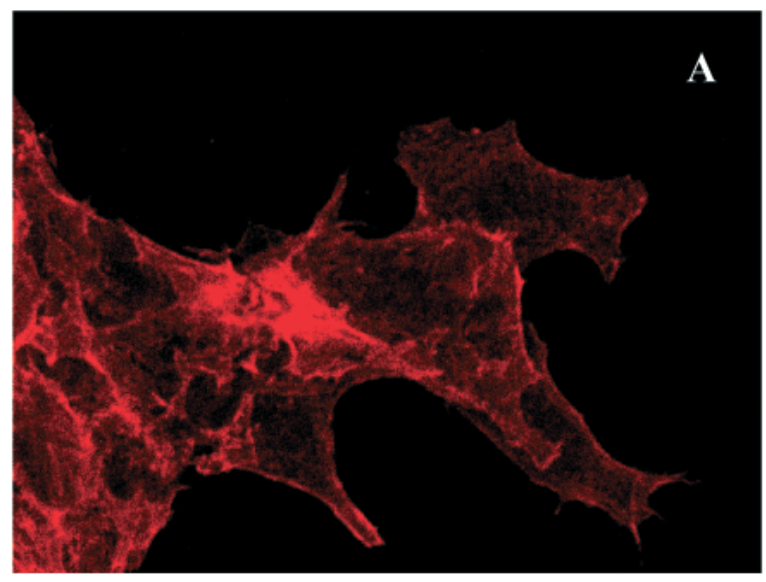

phalloidin were compared with those for the $\beta$ isoform visualization. Differences in $\beta$-actin subcellular localization between rounded and elongated cells were observed. In the elongated cells - the parental LS180 and 3LNLN - this isoactin is dispersed in whole cell body, and clearly concentrates in pseudopods and the leading edges (Fig. 3B, C and H, I). In contrast, in the rounded variant EB3, $\beta$-actin dominates mainly in the cortical ring under the cellular membrane and it is also seen in subtle protrusions (Fig. 3E, F). A distinct $\beta$-actin submembrane localization is not, however, clearly seen in the rounded $5 \mathrm{~W}$ cells (Fig. 3K, L), thus resembling its distribution in the LS180 and 3LNLN cells.

Adhesion and locomotion are one of the key capabilities of tumor cells allowing metastasis formation. The concept that tumor invasion is a disease of dysregulated cell motility has gained recognition over the past few years (Kassis et al., 2001; Sahai \& Marshall, 2003; Lambrechts et al., 2004; Buda \& Pignatelli, 2004). The enhanced movement of malignant tumor cells that invade and destroy normal tissue architecture is a major contributor to the progression of cancer, with many cells found in secondary tumors at sites distant from their origin. The acquisition of migratory and invasive properties are the key events in the oncogenic progression of cells (Wyckoff et al., 2000; Sahai \& Marshall, 2003). Those movements and alteration in the cell shape of oncogenically activated cells present a very complicated process. It requires spatially and temporally regulated protease secretion, alteration of integrin expression, modification of actin linking proteins, and coordinated activation of the actin cytoskeleton, resulting in the extension of invadopodia and cell locomotion (Kassis et al., 2001; Lambrechts et al., 2004).

The problem of the functional differentiation of actin isoforms and their subcellular distribution attracts permanent attention. There are data suggesting that actin isoforms serve unique functions in the

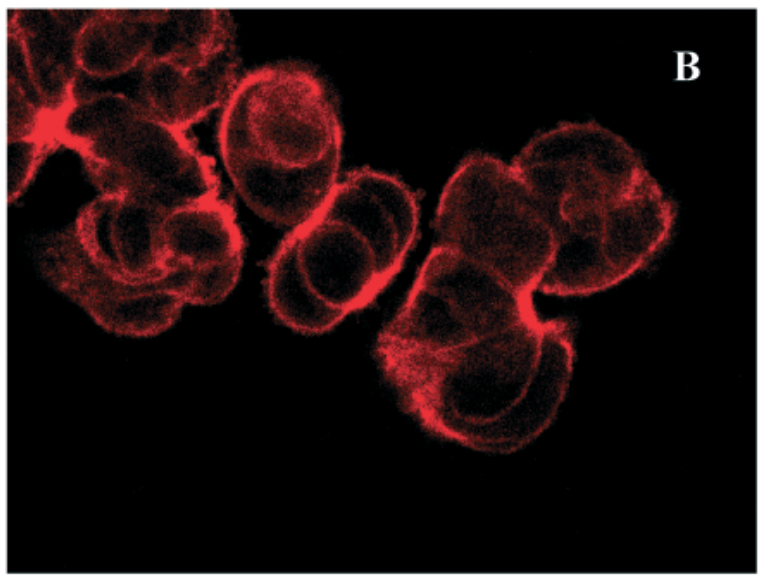

Figure 4. Visualization of filamentous actin by confocal microscopy.

Rhodamine-phalloidin staining, scale bar, $10 \mu \mathrm{m}$; obj. 40×. A, LS180; and B, EB3 cells. 
cells and that their activity might be controlled by actin binding proteins (ABP). These proteins are able to distinquish one actin from another, thereby causing the differential regulation of the dynamics and localization of isoactins (Welch \& Herman, 2002). Overexpression of $\beta$-actin not only increases cell locomotion but also produces a qualitative change in its mechanism, particularly in that of protrusion (Peckham et al., 2001). Regulation of $\beta$-actin expression and function seems to be an important parameter determining pseudopodial protrusion and invasiveness of tumor cells (Le et al., 1998).

We have observed earlier an increased state of actin polymerization (measured as F:G actin ratio) in human adenocarcinoma cell variants characterized by higher metastatic potential (EB3, 3LNLN and 5W) compared with the parental LS180 cells (Nowak et al., 2002). The current study confirms the submembrane distribution of $\beta$-actin i.e. its concentration in the most dynamic cellular area. It forms there the distinct cortical ring in the rounded EB3 cells. This type of actin organization will support movement by "bleb formation" (Keller \& Bebie, 1996; Keller \& Eggli, 1998; Sahai \& Marshall, 2003 ). The results confirm also the correlation between the increase in $\beta$-actin level and the higher motility of the cells, as expressed distinctly in the EB3 human adenocarcinoma selectants. This subline allowed selection of further variants of high metastatic potential (3LNLN and 5W).

The role of the actin cytoskeleton in the motility of normal and pathological cells has been summarized lately by Lambrechts et al. (2004). Actinbased cell motility relies on balanced activity of specific actin binding proteins (ABP), for example cofilin/ADF, profilin, thymosin and myosins (Rędowicz, 2002; Lambrechts et al., 2004), that drive the dynamics of the actin system and govern its spatial organization. Several valuable models have been proposed to try to grasp the combined cellular action of these proteins (Kassis et al., 2001; Sahai \& Marshall, 2003; Welch \& Herman, 2002; Wong et al., 2003; Honda et al., 2005), as only such an approach will unravel the cellular migration phenomena. There is no single model to describe cell motility. Different aspects of motile behavior are displayed depending on the cell type or environment. Different ABPs are known to respond to different signaling pathways (Hood \& Cheresh, 2002; Sakai \& Marshall, 2003; Buda \& Pignatelli, 2004).

In summary - our earlier (Nowak et al., 2002) and current data lead to the conclusion that there is a distinct correlation between the metastatic capacity of the examined human colon adenocarcinoma cells and the state of actin polymerization, actin cytoskeleton organization and $\beta$-actin expression.

Understanding of the molecular mechanisms responsible for the differences in the metastatic ca- pacity of specific cancer cells requires the correlation of data on actin level, polymerization, isoform expression and the specificity of interaction of the actin isoforms with ABPs. In respect to the very complex mechanism of regulation of actin polymerization, one has to concentrate on ABPs, interacting specifically with the $\beta$-actin isoform (Welch \& Herman, 2002; Wong et al., 2003; Sahai \& Marshall, 2003) and on their regulatory effect on $\beta$-actin polymerization.

\section{Acknowledgements}

The authors kindly thank Professor D. Duś and Dr. A. Krawczenko from the Institute of Immunology and Experimental Therapy, Polish Academy of Sciences in Wrocław for making the cells available.

\section{REFERENCES}

Bond M, Somlyo AV (1982) Dense bodies and actin polarity in vertebrate smooth muscle. J Cell Biol 95: 403-413.

Bradford MM (1976) A rapid and sensitive method for the quantitation of microgram quantities of protein utilizing, the principle of protein-dye binding. Anal Biochem 272: $248-254$.

Buda A, Pignatelli M (2004) Cytoskeletal network in colon cancer: from genes to clinical application. Int J Biochem 36: 759-765.

Button E, Shapland C, Lawson D (1995) Actin, its associated proteins and metastasis. Cell Motil Cytoskel 30: 247-251.

Chaponnier C, Gabbiani J (2004) Pathological situations characterized by altered isoform expression. J Pathol 204: 386-395.

Herman IM (1993) Actin isoforms. Curr Opin Cell Biol 5: 48-55.

Honda K, Yamada T, Hayashida $\mathrm{Y}$, Idogawa M, Sato S, Hasegawa F, Ino Y, Ono M, Hirohashi S (2005) Actinin4 increases cell motility and promotes lymph node metastasis of colorectal cancer. Gastroenterology 128: 51-62.

Hood JD, Cheresh DA (2002) Role of integrins in cell invasion and migration. Nat Rev 2: 91-100.

Janmey PA, Chaponnier C (1995) Medical aspects of the actin cytoskeleton. Curr Opin Cell Biol 7: 111-117.

Kassis J, Lauffenburger DA, Turner T, Wells A (2001) Tumour invasion as dysregulated cell motility. Cancer Biol 11: 105-117.

Keller HU, Bebie H (1996) Protrusive activity quantitatively determines the rate and direction of cell locomotion. Cell Motil Cytoskel 33: 241-251.

Keller H, Eggli P (1998) Actin accumulation in pseudopods or in the tail of polarized walker carcinosarcoma cells quantitatively correlates with local folding of the cell surface membrane. Cell Motil Cytoskel 40: 342-353.

Khatilina S (2001) Functional specificity of actin isoforms. Inter Rev Cytol 202: 35-98.

Kieda C, Paprocka M, Krawczenko A, Załęcki P, Dupuis P, Monsigny M, Radzikowski C, Duś D (2002) New human microvascular endothelial cell lines with specific adhesion molecules phenotypes. Endothelium 9: 247-261.

Laemmli UK (1970) Cleavage of structural proteins during the assembly of the head of bacteriophage T4. Nature 227: $680-685$. 
Lambrechts A, Van Troys M, Ampe C (2004) The actin cytoskeleton in normal and pathological motility. Int $\mathrm{J} \mathrm{Bi}$ ochem Cell Biol 36: 1890-1909.

Le PU, Nguyen TN, Drolet-Savoie P, Leclerc N, Nabi LR (1998) Increased $\beta$-actin expression in an invasive Moloney sarcoma virus-transformed MDCK cell variant concentrates to the tips of multiple pseudopodia. Cancer Res 58: 1631-1635.

Malicka-Błaszkiewicz M, Roth JS (1981) Some factors affecting the interaction between actin leukemia L1210 cells and DNase I. Biochem Biophys Res Commun 102: 594-601.

Malicka-Błaszkiewicz M, Styczeń I, Nowak D, Hańczycowa H, Ponikowski P, Sebzda T (1995) Actin content and polymerization in tumor, liver and serum of the hepatoma Morris 5123 tumor bearing rats. Mat Med Pol 27: 115-118.

Nagata K, Ichikawa Y (1984) Changes in actin during differentiation. Cell Muscle Motil 5: 171-193.

Nguyen TN, Wang HJ, Zalzal S, Nanci A, Nabi IR (2000) Purfication and characterization of $\beta$ actin-rich tumor cell pseudopodia: role of glycolysis. Exp Cell Res 258: 171-183.

Nowak D, Majcher I, Kochman A, Malicka-Błaszkiewicz M (1995) The changes in actin content and polymerization during hepatoma Morris 5123 tumor development. J Exp Clin Cancer Res 14: 37-40.

Nowak D, Kochman A, Malicka-Błaszkiewicz M (1999) Identification of actin from hepatoma Morris 5123 cells. Acta Biochim Polon 46: 949-959.

Nowak D, Malicka-Błaszkiewicz M (1999) Izoformy aktyny - zróżnicowanie funkcji, zmiany w stanach patologicznych. Post Biochem 45: 261-269 (in Polish).

Nowak D, Krawczenko A, Duś D, Malicka-Błaszkiewicz M (2002) Actin in human colon adenocarcinoma cells with different metastatic potential. Acta Biochim Polon 49: 823-828.

Opolski A, Wietrzyk J, Duś D, Kieda C, Matejuk A, Makowska A, Wojdat E, Ugorski M, Laskowska A, Kłopocki A, Rygaard J, Radzikowski C (1998) Metastatic potential and saccharide antigens expression of human colon cancer cells xenotransplanted into athymic nude mice. Folia Microbiol 43: 507-510.

Otrocka M, Verschueren H, Malicka-Błaszkiewicz M (2001) The effect of methotrexate on actin and invasiveness of hepatoma Morris 5123 cells in culture. Acta Biochim Polon 48: 1051-1060

Peckham M, Miller G, Wells C, Zicha D, Dunn GA (2001) Specific changes to the mechanism of cell locomotion induced by overexpression of $\beta$ actin. J Cell Sci 114: 1367-1377.
Pokorna E, Jordan PW, O'Neill CH, Zicha D, Gilbert CS, Vesely P (1994) Actin cytoskeleton and motility in rat sarcoma cell populations with different metastatic potential. Cell Motil Cytoskel 28: 25-33.

Rędowicz MJ (2002) Myosins and pathology: genetics and biology. Acta Biochim Polon 49: 789-804.

Sahai E, Marshall CJ (2003) Differing modes of tumour cell invasion have distinct requirements for Rho/ROCK signaling and extracellular proteolysis. Nat Cell Biol 5: $711-719$

Shestakova EA, Wyckoff J, Jones J, Singer RH, Condeelis J (1999) Correlation of $\beta$-actin messenger RNA localization with metastatic potential in rat adenocarcinoma cell lines. Cancer Res 59: 1202-1205.

Sheterline P, Clayton J, Sparrow JC (1998) Protein Profile. Actin, Oxford University Press, New York.

Stournaras C, Stiakaki E, Koukouritaki SB, Theodoropoulos PA, Kalmanti M, Fostinis Y, Gravanis A (1996) Altered actin polymerization dynamics in various malignant cell types: evidence for differential sensitivity to cytochalasin B. Biochem Pharmacol 52: 1339-1346.

Suzuki H, Nagata H, Shimada Y, Konno A (1998) Decrease in $\gamma$-actin expression, disruption of actin filaments and alterations in cell adhesion in human salivary gland adenocarcinoma cell clones. Int J Oncol 12: 1079-1084.

Towbin H, Stachelin T, Gordon T (1979) Electrophoretic transfer of proteins from polyacrylamide gels to nitrocellulose sheets: procedure and some applications. Proc Natl Acad Sci USA 76: 466-472.

Vandekerckhove J, Weber K (1978) At least six different actins are expressed in a higher mammal: An analysis based on the aminoacids sequence of the amino-terminal tryptic peptide. J Biol Chem 126: 783-802.

Verschueren H, Van Der Taelen I, Dewit J, De Braekeleer J, De Beatselier P (1994) Metastatic competence of BW5147 T-lymphoma cell lines is correlated with in vitro invasiveness, motility and F-actin content. J Leukoc Biol 55: 552-556.

Welch AY, Herman IM (2002) Cloning and characterization of $\beta C A P 73$, a novel regulator of $\beta$ actin assembly. Int J Biochem Cell Biol 34: 864-881.

Wong K, Rubenthiran U, Jothy S (2003) Motility of colon cancer cells: modulation by CD44 isoform expression. Exp Mol Pathol 75: 124-130.

Wyckhoff JB, Jones JG, Condeelis JS, Segall JE (2000) A critical step in metastasis: in vitro analysis of intravasation at the primary tumor. Cancer Res 60: 2504-2511. 